\title{
Postpartum contraceptive use in Gondar town, Northwest Ethiopia: a community based cross-sectional study
}

\author{
Yeshewas Abera', Zelalem Birhanu Mengesha ${ }^{2}$ and Gizachew Assefa Tessema ${ }^{2 *}$
}

\begin{abstract}
Background: Addressing family planning in the postpartum period is crucial for better maternal, neonatal and child survival because it enables women to achieve healthy interval between births. The contraceptive behavior of women in the postpartum period is usually different from other times in a woman's life cycle due to the additional roles and presence of emotional changes. Therefore, this study is conducted with the aim of assessing the contraceptive behavior of women in the postpartum period.
\end{abstract}

Methods: A community-based cross-sectional study was conducted in August 2013 among women who gave birth one year before the study period in Gondar town, Northwest Ethiopia. Multistage cluster sampling technique was employed to recruit a total of 703 study participants. For data collection, a structured and pretested questionnaire was used. Descriptive statistics were done to characterize the study population using different variables. Bivariate and multiple logistic regression models were fitted. Odds ratios with 95\% confidence intervals were computed to identify factors associated with contraceptive use.

Results: Nearly half (48.4\%) of the postpartum women were using different types of contraceptives. The most commonly used method was injectable (68.5\%). Resumption of mensus [Adjusted Odds Ratio (AOR) $=8.32$ 95\% Confidence Interval $(\mathrm{Cl}):(5.27,13.14)]$, age $\leq 24$ years $[\mathrm{AOR}=2.36,95 \% \mathrm{Cl}:(1.19,4.69)$, duration of $7-9$ months after delivery $[A O R=2.2695 \% \mathrm{Cl}:(1.12,4.54)]$, and having antenatal care $[A O R=5.76,95 \% \mathrm{Cl}:(2.18,15.2)]$ were the factors positively associated with contraceptive use in the extended postpartum period.

Conclusion: Postpartum contraceptive practice was lower as compared to the Ethiopian demographic and health survey 2011 report for urban areas. Strengthening family planning counseling during antenatal care visit and postnatal care would improve contraceptive use in the postpartum period.

Keywords: Contraception, Postpartum period, Ethiopia

\section{Background}

Maternal health problems remain a major global concern since pregnancy and childbirth are the leading causes of morbidity and mortality among reproductive age women. According to 2013 maternal mortality estimate 292, 982 maternal deaths occurred during 2013 and almost $99 \%$ of these deaths happened in the developing countries [1]. Moreover, $90 \%$ of the neonatal death registered in these countries [2]. According to the Ethiopian

\footnotetext{
* Correspondence: agizachew@gmail.com

${ }^{2}$ Department of Reproductive Health, Institute of Public Health, University of Gondar, Gondar, Ethiopia

Full list of author information is available at the end of the article
}

Demographic and Health Survey (EDHS) 2011, the maternal mortality ratio is 676 per 100,000 live births [3].

Evidences have shown that encouraging early antenatal care visits, institutional deliveries, postnatal care, and contraceptive adoption are the key elements in improving safe motherhood. As the first pillar of safe motherhood and an essential component of primary health care, contraceptive plays a key role in reducing maternal and newborn morbidity and mortality by preventing unintended pregnancy and close birth intervals [4].

World Health Organization (WHO) technical committee advices an interval of at least 24 months before couples attempt to become pregnant [2]. A closed birth interval 
would endanger the lives of the mother, the newborn, and the (previously delivered child). When a mother becomes pregnant shortly after childbirth, she is more likely to develop complications including spontaneous abortion, postpartum bleeding, and anemia. Secondly, the newborn could be born low birth weight and/or preterm. Thirdly, the index child (previously delivered child) might receive inadequate care and support which, thereafter, could lead to vulnerabilities to disease and malnutrition $[4,5]$.

In Ethiopia, nearly half of all non-first pregnancies occur less than 24 months following the preceding birth [6]. Another study done in Northwest Ethiopia also showed the presence of short intervals between births [7]. Hence, introduction of effective contraceptive method during the postpartum period is very crucial. Studies have revealed that the first year following delivery is so complex and different from other times in a woman life cycle due to additional burden to care her infant and series of emotional and physical changes $[6,8,9]$. These women would also perceive a low risk of pregnancy $[10,11]$.

The Ethiopian Health Sector Development Program (HSDP) IV sets a goal of improving maternal health and increasing family planning coverage. However, the first year after birth is given less emphasis regarding contraceptive utilization [12]. Therefore, this study can help health planners and policy makers to develop effective strategies for the prevention of closely spaced and unintended pregnancies.

\section{Methods}

\section{Study setup}

A community-based cross-sectional study was conducted in August 2013 at Gondar town. The town is located 727 kms Northwest of Addis Ababa, capital of Ethiopia. It is divided in to 12 administrative areas. According to the 2013 population projection estimate, there were 258,178 residents and more than half of them were females. Using the conversion factor of $2.77 \%$ to estimate the number of women having less than one years old, the estimated number of postpartum women were 5,734 [13]. There are three hospitals and eight health centers providing maternal and other health services to the population. Postpartum women (from 6 weeks to one year of extended postpartum period) who gave birth one year prior to the study period and not pregnant were included in this study.

\section{Sample size calculation and sampling procedure}

The single population proportion formula was used to calculate the sample size considering the following assumptions: Since there is no study in Ethiopia, the proportion of women using contraceptives in the postpartum period was assumed to be $50 \%, 95 \%$ confidence level, $5 \%$

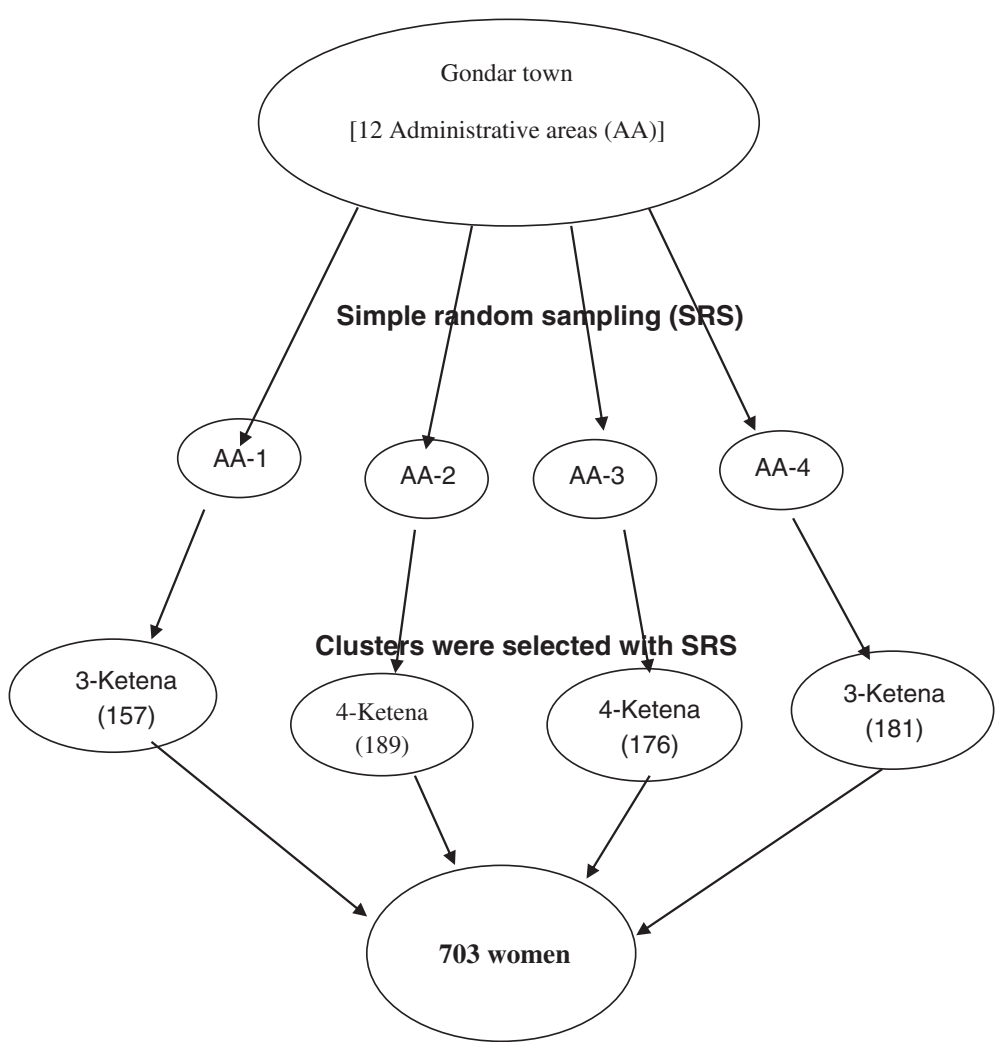

Figure 1 Schematic representation of the sampling procedure. *AA- Administrative areas. 
margin of error (absolute level of precision). In the recruitment of the study participants, the present study has undertaken multistage cluster sampling technique. In the case of multi-stage sampling approach, design effect should be accounted for the possible presence of intercluster variability. With this regard, design effect can be assumed equivalent to the number of stages that had been undergone to reach the final respondents (here there are two stages). However, due to limited resource to conduct the study, we minimized our design effect to 1.5 , instead of two. In addition, a non-response rate $10 \%$ was considered and finally a sample size of 634 was calculated. In the process of reaching to the individual study participant, a lottery method was employed to select four of the twelve administrative areas. Then, three to four ketenas (clusters) in the selected four administrative areas were again randomly selected. Finally, all women in the extended postpartum period were interviewed in each cluster. This made the final number of respondents to be 703 (Figure 1).

\section{Data collection and analysis}

Data were collected using a structured and pretested questionnaire via face-to-face interview at the participant's home. The questionnaire was first prepared in English and then translated into local language (Amharic), and back to English to ensure consistency. Five midwifery nurses and one supervisor were involved in the data collection process. Local guiders were also participated in recruiting eligible women. Two days training was given to the data collectors and supervisor.

Data were entered using EPI-INFO version 3.5.3 and exported to SPSS version 20 statistical software for further analysis. Descriptive statistics were carried out to characterize the study population using different variables. Both bivariate and multiple logistic regressions were used to identify associated factors. Variables having $\mathrm{p}$ value $\leq 0.2$ in the bivariate analyses were fitted into a multiple logistic regression model to control the effects of confounding. Crude and adjusted odds ratio with their 95\% CI were calculated to determine the strength and presence of association. P value of 0.05 was considered to declare the level of significance.

\section{Ethical considerations}

Ethical clearance was obtained from the Institutional Review Board of the Institute of Public Health, University of Gondar. An official letter of cooperation was written to Gondar town administration. After explaining the purpose of the study, verbal informed consent was obtained from each of the participant. Participants were also informed that participation was on voluntary basis and that they can withdraw at any time if they are not comfortable about the questionnaire. Personal identifiers were not included in the written questionnaires to ensure participants' confidentiality.

\section{Results}

Socio-demographic characteristics of the respondents In this study, 705 women who met the eligibility criteria were included. From these, 703 women responded to the

Table 1 Socio-demographic characteristics of the study participants at Gondar town, August 2013 ( $n=703$ )

\begin{tabular}{|c|c|c|}
\hline Variable & Frequency & Percent \\
\hline \multicolumn{3}{|l|}{ Age } \\
\hline $15-19$ & 36 & 5.1 \\
\hline $20-24$ & 198 & 28.2 \\
\hline $25-29$ & 259 & 36.8 \\
\hline $30-34$ & 108 & 15.4 \\
\hline$\geq 35$ & 102 & 14.5 \\
\hline \multicolumn{3}{|l|}{ Marital status } \\
\hline Married & 606 & 86.2 \\
\hline Single & 46 & 6.5 \\
\hline Separated/widowed/divorced & 51 & 7.3 \\
\hline \multicolumn{3}{|l|}{ Educational attainment } \\
\hline No formal education & 154 & 21.9 \\
\hline Primary education & 203 & 28.9 \\
\hline Secondary education & 201 & 28.6 \\
\hline Tertiary education & 145 & 20.6 \\
\hline \multicolumn{3}{|c|}{ Husband Educational attainment $(n=606)^{*}$} \\
\hline No formal education & 42 & 6.9 \\
\hline Primary education & 113 & 18.6 \\
\hline Secondary education & 241 & 39.8 \\
\hline Tertiary education & 210 & 34.7 \\
\hline \multicolumn{3}{|l|}{ Religion } \\
\hline Orthodox Christian & 577 & 82.1 \\
\hline Muslim & 107 & 15.2 \\
\hline Other** & 19 & 2.7 \\
\hline \multicolumn{3}{|l|}{ Ethnicity } \\
\hline Amhara & 672 & 95.6 \\
\hline Tigre & 30 & 4.3 \\
\hline Oromia & 1 & 0.1 \\
\hline \multicolumn{3}{|l|}{ Occupational status } \\
\hline House wife & 373 & 53.1 \\
\hline Government employee & 130 & 18.5 \\
\hline Merchant & 92 & 13.1 \\
\hline Student & 46 & 6.5 \\
\hline Daily laborer & 56 & 8.0 \\
\hline Other ${ }^{* * *}$ & 6 & 0.9 \\
\hline
\end{tabular}

${ }^{*}$ Among those married women **Protestant and Judaism ***job seekers, Tella (alcohol) sellers. 
Table 2 Reproductive health and maternal health service related characteristics of study participants at Gondar town, August $2013(n=703)$

\begin{tabular}{lll}
\hline Variable & Frequency & Percentage \\
\hline Living children & & \\
1 & 294 & 41.8 \\
$2-3$ & 322 & 45.8 \\
$\geq 4$ & 87 & 12.4
\end{tabular}

Fertility Desire

Yes 379

No 324

53.9

46.1

Birth interval (in months) $(n=409)^{*}$

$<24$

24-47

$\geq 48$

Reproductive Intention

Want to have space

Want to limit

Undecided

Want to have a child soon

Menses Return

Yes

\section{Postpartum period}

6th week-3rd month

4th-6th month

7th-9th month

10th-12th month

Resume sexual intercourse

Yes

No

ANC follow up

Yes

No

Number of visit $(n=631)^{* *}$

1 visit

2-3 visit

$\geq 4$ visit

Place of delivery

Government facility

Private health facility

Home

Postnatal care

Yes

No
Table 2 Reproductive health and maternal health service related characteristics of study participants at Gondar town, August 2013 ( $n=703$ ) (Continued)

FP counseling during $\mathrm{PNC}^{* * *}$

\begin{tabular}{lcc} 
Yes & 112 & 60.5 \\
No & 74 & 39.5 \\
\hline${ }^{*}$ Among those who have previous child. ${ }^{* *}$ Among women attending ANC \\
${ }^{* * *}$ Among PNC attendees.
\end{tabular}

questionnaire making the response rate $99.7 \%$. The mean age of respondents was 27.2 years $(\mathrm{SD}=5.7)$. Two hundred fifty nine (36.8\%) were aged between 25-29 years. The majority $(86.2 \%)$ of the respondent were married. Most (95.6\%) were Amhara by ethnicity and $82.1 \%$ were Orthodox Christians. Three hundred seventy three (53.1\%) were housewives. More than a quarter (28.9\%) attended primary school and $39 \%$ of the partners attended secondary school (Table 1).

\section{Reproductive health characteristics of participants}

The median number of living children was 2.1 per women $(\mathrm{IQR}=1.1,3.0)$. Two hundred ninety four $(41.8 \%)$ had only one child. Three hundred and seventy nine (53.9\%) did not have desire to have additional children. The median duration of birth interval was 36 months $(\mathrm{IQR}=24$, 48). Three hundred twenty four (46\%) of the respondents did not have intention to have more children. More than half $(53.1 \%)$ had regular menses. Five hundred two (71.4\%) of them had resumed sexual intercourse. One-third (33\%) of the respondents were in between 10th-12th month of postpartum period (Table 2).

Maternal health service utilization during last pregnancy The majority (89.8\%) had ANC attendance. From the ANC attendants, 509 (80.7\%) had four or more visits. Six hundred forty eight (92.2\%) respondents delivered in health facilities. Five hundred fifteen (82.6\%) received the service from public health facilities. Among those who had attended ANC, around half (50.2\%) were given counseling about family planning. More than a quarter $(26.3 \%)$ had taken postnatal care service. About a quarter of women (26.3\%) were attended postnatal care. One hundred and twelve (60.9\%) of the participants received family planning counseling at postnatal care sessions. Two-thirds $(66.6 \%)$ of the participants had knowledge on Lactational Amenorrhea Method (LAM) (Table 2).

\section{Contraceptive use in the postpartum period}

The prevalence of contraceptive use was found to be 340 (48.4\%) [95\% CI: $(44.5,52.1)$ ]. Injectable contraceptive $233(68.5 \%)$ and oral contraceptive pills 57 (16.8\%) were the most frequently used methods. Among the users, 265 (78\%) were using contraception to space their 


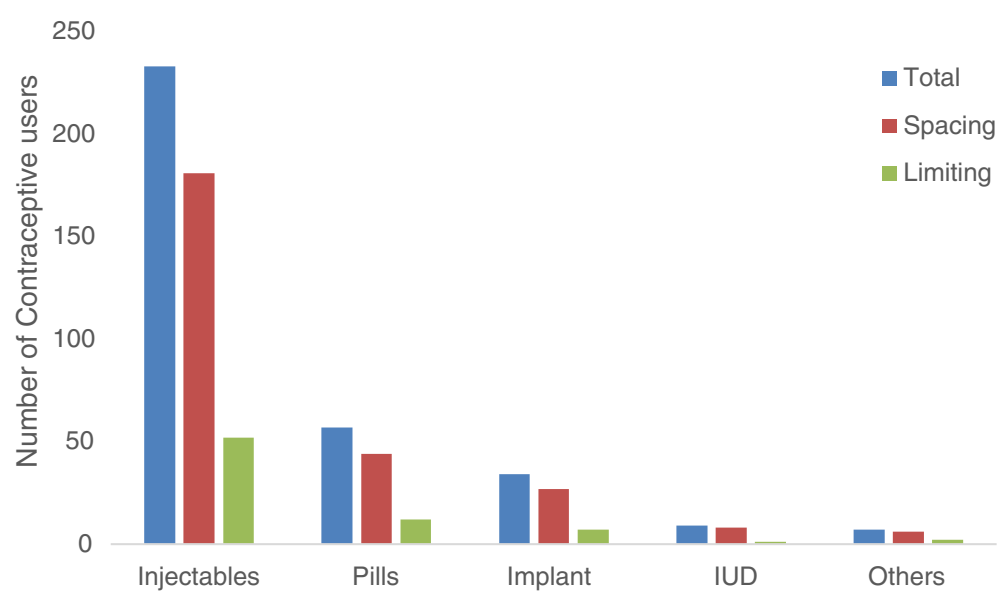

Figure 2 Number of contraceptive users by purpose among postpartum women in Gondar town, Northwest Ethiopia, August, 2013 $(n=340)$.

births (Figure 2). Among contraceptive users, 60.5 percent started contraceptive use after the menses resumed. Two hundred forty-eight (72.9\%) collected their contraceptives from public health facilities. Two hundred and sixty $(76.4 \%)$ of the contraceptive users made contraceptive decisions jointly with their partners.

\section{Reasons for not using contraceptive methods}

Less perceived risk for pregnancy (49\%) and spousal absence $(16.8 \%)$ were the main reasons for not using contraceptive methods (Figure 3).

\section{Factors associated with postpartum contraceptive use}

In the multiple logistic regression analysis, age of the women, duration after delivery, menses resumption, and ANC visit showed significant and independent association with postpartum contraceptive use. The odds of using contraceptive were 2.3 times higher among women age $<24$ years as compared to those who were 35 years or more $[\mathrm{AOR}=2.36,95 \% \mathrm{CI}: 1.19,4.69]$. The odds of using contraceptive were about 2.3 times higher in women 7-9 months after delivery than women between 6 weeks3 months of postpartum $[\mathrm{AOR}=2.2695 \%$ of $\mathrm{CI}$ : $(1.12$, 4.54)]. The odds of using contraceptive in menstruating women were about eight times higher than nonmenstruating ones $[\mathrm{AOR}=8.32$ 95\% CI: $(5.27,13.14)]$. Women who obtained ANC were about five times higher odds to use contraceptive than who did not $[\mathrm{AOR}=5.23$, 95\% CI: $(2.04,13.42)]$. Women who were attended postnatal care were about two times higher odds to use contraceptive that those who did not $[\mathrm{AOR}=1.63,95 \%$ CI: (1.01, 2.61)] (Table 3).

\section{Discussion}

Women in the postpartum period have a critical window of opportunity to receive family planning service especially in urban areas because of their better access to health services including ANC, delivery, postnatal care, and immunization $[10,14]$.

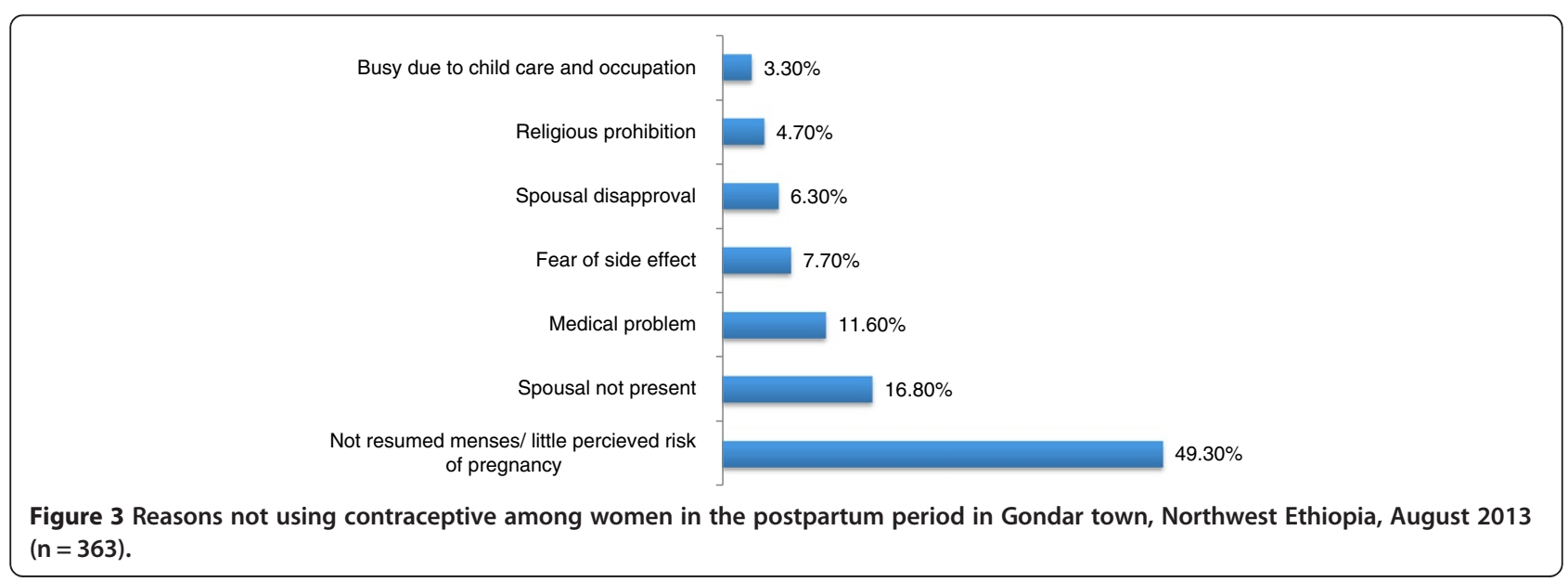


Table 3 Crude and adjusted odds ratios (OR) and 95\% confidence intervals (CI) of factors associated with contraceptive use during postpartum period, Gondar town, August, $2013(\mathbf{n}=703)$

\begin{tabular}{|c|c|c|c|c|c|}
\hline \multirow[t]{2}{*}{ Variable } & \multicolumn{2}{|c|}{ Contraceptive use } & \multirow[t]{2}{*}{ COR $(95 \% \mathrm{Cl})$} & \multirow[t]{2}{*}{ AOR $(95 \% \mathrm{Cl})$} & \multirow[t]{2}{*}{$P$ value } \\
\hline & Yes & No & & & \\
\hline Age & & & & & 0.00 \\
\hline$\leq 24$ & 125 & 109 & $2.29(1.41,3.73)$ & $2.5(1.04,6.04)^{*}$ & \\
\hline 25-34 & 181 & 186 & $1.95(1.23,3.08)$ & $1.71(0.8,3.65)$ & \\
\hline$\geq 35$ & 34 & 68 & 1 & 1 & \\
\hline Marital status & & & & & 0.62 \\
\hline Not currently married & 23 & 74 & 1 & 1 & \\
\hline Currently Married & 317 & 289 & $2.53(2.15,5.79)$ & $2.01(0.66,5.01)$ & \\
\hline Educational attainment & & & & & 0.58 \\
\hline No formal education & 54 & 100 & 1 & 1 & \\
\hline Primary education & 104 & 99 & $1.96(1.27,2.99)$ & $1.27(0.58,2.74)$ & \\
\hline Secondary \& above & 182 & 164 & $2.06(1.39,3.04)$ & $1.98(0.46,2.12)$ & \\
\hline Partner educational attainment & & & & & 0.68 \\
\hline No formal education & 16 & 26 & 1 & & \\
\hline Primary education & 52 & 61 & $1.39(0.67,2.86)$ & $0.68(0.26,1.76)$ & \\
\hline Secondary and above & 249 & 202 & $2.0(1.05,3.84)$ & $0.84(0.32,2.27)$ & \\
\hline Number of alive children & & & & & 0.117 \\
\hline 1 & 154 & 140 & 1 & 1 & \\
\hline $2-3$ & 158 & 164 & $0.87(0.63,1.2)$ & $1.67(0.97,2.88)$ & \\
\hline$\geq 4$ & 28 & 59 & $0.43(0.26,0.72)$ & $1.08(0.41,2.83)$ & \\
\hline Fertility desire & & & & & 0.062 \\
\hline Yes & 115 & 209 & $0.38(0.27,0.51)$ & $0.65(0.40,1.06)$ & \\
\hline No & 225 & 154 & 1 & 1 & \\
\hline Postpartum period & & & & & 0.034 \\
\hline 6 wk-3 month & 30 & 115 & 1 & 1 & \\
\hline 4-6 month & 63 & 83 & $2.91(1.73,4.89)$ & $1.2(0.67,2.48)$ & \\
\hline 7-9 month & 114 & 66 & $6.62(4.00,10.95)$ & $4.8(2.51,9.30)^{*}$ & \\
\hline 10-12 month & 133 & 99 & $5.15(3.19,8.31)$ & $1.9(1.0,3.65)$ & \\
\hline Menses return by the time of survey & & & & & 0.000 \\
\hline No & 70 & 260 & 1 & 1 & \\
\hline Yes & 270 & 103 & $9.73(6.87,13.8)$ & $9.2(5.85,14.63)^{*}$ & \\
\hline Place of delivery & & & & & 0.96 \\
\hline Home & 10 & 43 & 1 & 1 & \\
\hline Health institution & 330 & 318 & $4.46(2.2,9.03)$ & $1.02(0.37,2.81)$ & \\
\hline ANC care & & & & & 0.001 \\
\hline No & 10 & 64 & 1 & 1 & \\
\hline Yes & 330 & 299 & $8.88(4.20,18.83)$ & $6.61(2.57,17.00)^{*}$ & \\
\hline Postnatal care & & & & & 0.042 \\
\hline No & 233 & 285 & 1 & 1 & \\
\hline Yes & 107 & 78 & $1.68(1.19,2.36)$ & $1.63(1.01,2.61)$ & \\
\hline LAM knowledge & & & & & 0.16 \\
\hline No & 137 & 182 & 1 & 1 & \\
\hline Yes & 203 & 181 & $1.49(1.11,2.01)$ & $0.72(0.45,1.13)$ & \\
\hline
\end{tabular}

*p value $<0.05$. 
This study revealed that nearly half $(48.4 \%)$ of the participants were using one form of contraceptives. This finding is slightly lower as compared to the 2011 EDHS report for urban women in Ethiopia (52.5\%) [3] even though these populations are somehow different from the population in the present study. However, this finding is consistent with studies done in Kenya and Zambia (46\%), Mexico (47\%), and Rwanda (50.4\%) [15-17]. Injectable (68.5\%) and pills (16\%) were the commonly used methods. Moreover, long acting methods accounted for $12.9 \%$ of the users. This would be attributed to client's preferences for a specific method [17]. These predominant methods have been observed in different studies $[3,11,18]$.

The present study revealed a significant difference in contraceptive use among the different age groups. The odds of using contraceptive were higher among women aged $<24$ years than who were 35 years or more. This could be explained by the fact that young women are more sexually active than older women do. A study done in sub-Saharan countries supported this finding [9].

Women whose menses resumed had higher odds to use contraceptive than ammenorrhic women. This might be explained by the fact that ammenhorric women would underestimate the risk of pregnancy by assuming that amenorrhea could guarantee protection against pregnancy regardless of the time of postpartum period. With this regard, in the current study about half (49.3\%) of the participants mentioned being ammenhoric as a reason for not using contraceptive. Similar finding was reported from a study done in Kenya [19].

Duration of the postpartum period showed a significant association with contraceptive use. Those women between 7-9 months of postpartum period had higher odds to use contraceptive when compared to women in the 6 weeks -3 months postpartum period. Contrary to this finding, the first three months of postpartum period was reported to be a predictor of contraceptive use [20]. However, consistent results were reported from studies done in Kenya [19] and Bangladesh [21]. This finding could be justified by the fact that most women had resumed menses after 6 months. The other possible reason could be that majority of women were abstainers in the first three months of postpartum period.

ANC utilization was the other important variable affecting contraceptive use. The possible explanation is women who attend antenatal care are more likely to get information towards contraceptive use. This is consistent with a prospective study done in Kenya and Zambia [22]. Studies in Mexico, India and United State of America have shown that FP counseling during prenatal care would motivate women to practice contraceptives $[16,20,23]$. Those women who were attended postnatal care had higher odds of using contraceptive in postpartum period. This is explained due to that postnatal visit may give the opportunity for contraceptive counseling and adoption in the postpartum period.

This study has some limitations. It mainly focuses on individual level factors. Factors related to the health system and the service providers did not included in the current study. The sociocultural factors and related misconception on family planning did not assessed in this study. Though a sample size of 703 is perceived to be adequate in the present study, due to limited resource to conduct the study, we accounted a design effect of 1.5 in calculating the required sample size.

\section{Conclusions}

The contraceptive use among women in the postpartum period is lower than urban women population in Ethiopia. Resumption of menses, age $\leq 24$ years, duration of 7-9 months after delivery, and having antenatal care were factors positively associated with postpartum contraceptive use. Strengthening the integration of family planning with ANC and postnatal services is recommended to improve the utilization of contraceptives in the postpartum period.

\section{Competing interests}

The authors declare that they have no competing interests.

\section{Authors' contribution}

YA originated and wrote the proposal, participated in data collection, analyzed the data drafted the paper. ZBM and GAT approved the proposal with some revisions, participated in data analysis. YA, ZBM, and GAT revised subsequent drafts of the manuscript. All authors read and approved the final manuscript.

\section{Acknowledgement}

We would like to pass our gratitude to the University Gondar for the approval of ethical clearance and technical support. Then, we are very grateful for all women who participated in this study for their commitments.

\section{Author details}

${ }^{1}$ Mahiberehiwot for Social Development Organization, Gondar, Ethiopia. ${ }^{2}$ Department of Reproductive Health, Institute of Public Health, University of Gondar, Gondar, Ethiopia.

Received: 12 March 2014 Accepted: 4 February 2015

Published online: 22 February 2015

\section{References}

1. Kassebaum JN, Bertozzi-Villa A, Coggeshall S. Global, regional, and national levels and causes of maternal mortality during 1990-2013: a systematic analysis for the Global Burden of Disease Study 2013. Lancet. 2014;6736(14):60696-6.

2. WHO. Report of a WHO Technical Consultationon on Birth Spacing. Geneva: WHO; 2006.

3. CSA [Ethiopia] and ICF International: Ethiopia Demographic and Health Survey report 2011. Addis Ababa, Ethiopia and Calverton, Maryland, USA. In.; 2012.

4. Conde-Agudelo A, Belizán JM. Maternal morbidity and mortality associated with interpregnancy interval. BMJ. 2000;321:1255.

5. Subhi R, Ahmed H, Mawlood Z. Spacing effects on maternal-child health. Tikrit Med J. 2011;17(2):1-6

6. USAID MCHIP. Family planning needs during the first two years postpartum in the Ethiopia. Washington DC: USAID; 2013. 
7. Tessema GA, Zeleke BM, Ayele TA. Birth interval and its predictors among married women in Dabat District, Northwest Ethiopia: A retrospective follow up study. Afr J Reprod Health. 2013;17(2):39-45.

8. John A, William L. Contraceptive use, intention to Use and unmet need during the extended postpartum period. Int Fam Plan Perspect. 2001;27:20-7.

9. Stephenson R, Baschieri A, Clements S, Hennink M, Madise N. Contextual influences on modern contraceptive Use in Sub-Saharan Africa. Am J Public Health. 2007:97(7):1233-40.

10. Jhpiego. Postpartum Intrautraine contraceptive Device (PPIUD) services Family planning intiative. Maryland, USA: Jhpiego; 2010.

11. Global Health Brief. Family planning for postpartum women: Seizing a Missed Opportunity. Maryland, USA: John Hopkins Bloomberg School of Public Health; USAID; 2005

12. Federal Democratic Republic of Ethiopia, Ministry of Health. Health Sector Development Programme IV: 2010/11 - 2014/15. Addis Ababa, 2010.

13. Amhara Regional Health Bureau(ARHB): Amhara Regional Health Bureau Wereda Based plan 2005 .C, Bahir Dar, Ethiopia 2012

14. Thomas B, Richard J, Mary S. Efficacy of a New postpartum transition protocol for avoiding pregnancy. Am Board Fam Med. 2012;26:35-44.

15. Aurellie B, Elizabeth E, Ngabo F, Wesson J, Chen M. Getting to 70\%: barriers to modern contraceptive use for women in Rwanda. Int J Gynecol Obstet. 2013;11-15.

16. Barber L. Family planning advice and postpartum contraceptive use among low-income women in Mexico. Int Fam Plan Perspect. 2007;33(1):6-12.

17. USAID. A guide for monitoring and evaluting population- health enviroment program. I. Washington DC: USAID; 2007.

18. WHO. Medical eligibility criteria for contraceptive use. 4th ed. Geneva, Switzerland: World health organization; 2010

19. Ndugwa R, Cleland J, Madise N, Fotso J, Zulu E. Menstrual pattern, sexual behaviors, and contraceptive use among postpartum women in Nairobi urban slums. J Urban Health. 2011;88:S341-355.

20. Ellen K, Christina I, Helen P. Postpartum contraceptive use among adolescent mother in seven state. J Adolesc Health. 2013:52(3):278-83.

21. Salway S, Nurani S. Postpartum contraceptive use in Bangladesh: understanding users' perspectives. NCBI. 1998;29(1):41-57.

22. Mai D, David H. Relationship between Antinatal and postnatal care and post partum modern contraceptive method. BMC Health Service Res. 2013;13:6.

23. Sebastian MP, Khan ME, Kumari K, Idnani R. Increasing postpartum contraception in rural India: evaluation of a community-based behavior change communication intervation. Int Perspect Sex Reprod Health. 2012:38(2):68-77.

\section{Submit your next manuscript to BioMed Central and take full advantage of:}

- Convenient online submission

- Thorough peer review

- No space constraints or color figure charges

- Immediate publication on acceptance

- Inclusion in PubMed, CAS, Scopus and Google Scholar

- Research which is freely available for redistribution

Submit your manuscript at www.biomedcentral.com/submit 